\title{
Biological Effects of Music in Cancer Patients: Contributing to an Evidence-Based Practice
}

\author{
Gunnar Glauco De Cunto Carelli Taets , \\ Caroline Mignha Aben-Athar Fernandes, Lucas da Costa Torres, \\ Christian Marx Carelli Taets
}

\begin{abstract}
A systematic review was performed using the descriptors "music" and "cancer". The data indicate that the use of music in the context of cancer patients can reduce anxiety, improve depression, reduce acute and / or chronic pain, improve cardiorespiratory parameters and reduce fatigue.
\end{abstract}

Keywords: Music, Cancer, Biological Effects

\begin{abstract}
Introduction
In health care, music has always been present. Since the magical rituals of primitive medicine, sounds, rhythms, voices and musical instruments have been used aiming at cure of diseases and easing of their symptoms. To the time of the Enlightenment, based in physical principles used for a long time in musical instruments, the invention of thoracic percussion by Leopold Joseph Auenbruger, Austrian musician and physician, brought immense elucidation to medical semiology. Major popularity was obtained during the Great Wars, when injured soldiers were exposed to music in order to ease their physical and emotional pains. ${ }^{1}$
\end{abstract}

The use of music as adjuvant therapy in the care of patients with chronic diseases has had growing relevance in the last decades, not accidently: besides its recognized benefits in psychic, spiritual and social spheres, innumerable biological effects of music therapy have been used in managing comorbidities. The application of music in health care, however, is not deprived of accuracy and scientific method; on the contrary, by music therapy it is understood the clinical use of music to reach individual objectives within a therapeutic relation by a accredited professional. ${ }^{2}$ The mechanisms through which music improves the patient's clinical condition are not yet exactly described. Studies have pointed events from psychological to metabolic - however, regardless the path, the global benefit to the sick person is each day more solid. It is known that pain, for example, has both motivational-affective and cognitive-evaluative dimensions, therefore, any strategy capable of provoking emotions and arousing one's memories can alter his or her perceptions.

Amongst the diseases that have music therapy as a more present ally each day, cancer is one of the most prominents. Seeing the multidisciplinarity obviously required oncological contexts, integrative practices as a whole are more commonly debated and experienced. Furthermore, especially in regions where the access to health services and the longitudinality of care are still deficient, the sick are diagnosed with malignant tumors already in inoperable stages, frequently metastatic, bringing to health team the need of an approach whose priority is not cure, but quality of life throughout the weeks or month the patient will last. As for that, music stands out as valorous promise of comfort, with the benefit of being a noninvasive method, enabling testing of its multiple biological effects in patients with equally multiple symptoms: algic syndromes, nausea, variations in vital signs, depression, anxiety, between others.

Pondering such possibilities, the objective of this study is to investigate the biological effects of the use of music in patients with cancer already described in literature.

\begin{abstract}
Methods
The $\mathrm{PICO}^{3}$ strategy was used to elaborate the question "What are the biological effects of music in patients with cancer?", by which it was considered as Problem the patients with cancer; Intervention for music therapy; as Control patients who were not submitted to any therapy or who were submitted exclusively to conventional therapies chemotherapy, radiotherapy, surgical resection of the tumor, among others; and as Outcome any biological effect related to the intervention, estimated either by questionnaires answered by the patients, or by biochemical and molecular tests or standardized scales of symptom assessment.
\end{abstract}

Then, the electronic search was done by two independent researchers using the descriptors "music" and "cancer" and the Boolean connector 
"and", being included among the results clinical studies, clinical trials, comparative studies, metamulticenter studies, randomized controlled trials, systematic reviews and observational studies of the last ten years with complete and free text available in Portuguese, English or Spanish in the following databases: PubMed, Virtual Health Library (BVSalud) and CAPES Thesis Bank. The articles selected were those that addressed specific biological effects of the use of music as therapy in patients with malignant neoplasms. Subsequently, articles that were cited in more than one database were excluded and all references to eligible publications were analyzed. Thus, by grouping and analyzing results of primary studies carried out in different places and times by independent research groups, we integrated existing information on the subject, allowing the generation of scientific evidence from 30 articles that composed the study sample.

\section{Results and Discussion}

The following table presents the result of the systematic review from the data collected characterizing the sample from the title, author, year, country and methodology of the study. The articles will be described and numbered as A1, A2, A3, etc.

Table I - Characterization of the sample, 2019.

\begin{tabular}{|c|c|c|}
\hline Articles & País & Method \\
\hline $\mathrm{A} 1^{4}$ & United States of America & randomized controlled trial \\
\hline $\mathrm{A} 2^{5}$ & United States of America & Systematic review \\
\hline $\mathrm{A} 3^{6}$ & United States of America & randomized controlled trial \\
\hline $\mathrm{A} 4^{7}$ & Germany & Systematic review \\
\hline $\mathrm{A} 5^{8}$ & United States of America & randomized controlled trial \\
\hline A6 ${ }^{9}$ & Germany & randomized controlled trial \\
\hline $\mathrm{A} 7^{10}$ & United States of America & Case Study \\
\hline A $8^{11}$ & United States of America & Systematic review \\
\hline A9 ${ }^{12}$ & United States of America & Systematic review \\
\hline $\mathrm{A} 10^{13}$ & United States of America & Systematic review \\
\hline A1 $1^{14}$ & Netherlands & Clinical study \\
\hline $\mathrm{A} 12^{15}$ & China & Systematic review with meta-analysis \\
\hline A13 ${ }^{16}$ & Germany & Systematic review with meta-analysis \\
\hline A14 ${ }^{17}$ & Canada & Sistematic Review \\
\hline $\mathrm{A} 15^{18}$ & Hawaii & Integrative Review \\
\hline A $16^{19}$ & United States of America & Sistematic Review \\
\hline $\mathrm{A} 17^{20}$ & United States of America & Narrative review \\
\hline A1 $18^{21}$ & United States of America & Randomized Controlled Study \\
\hline $\mathrm{A} 19^{22}$ & United States of America & Review \\
\hline $\mathrm{A} 20^{23}$ & Brazil & Sistematic Review \\
\hline $\mathrm{A} 21^{24}$ & Poland & Review \\
\hline $\mathrm{A} 22^{25}$ & United States of America & Sistematic Review \\
\hline
\end{tabular}




\begin{tabular}{|l|c|l|}
$\mathrm{A} 23^{26}$ & United States of America & Non-randomized controlled trial \\
\hline $\mathrm{A} 24^{27}$ & United States of America & Sistematic Review \\
\hline $\mathrm{A} 25^{28}$ & Brazil & Integrative Review \\
\hline $\mathrm{A}^{26}{ }^{29}$ & Brazil & Integrative Review \\
\hline $\mathrm{A} 27^{30}$ & United States of America & Integrative Review \\
\hline $\mathrm{A} 28^{31}$ & United States of America & Integrative Review \\
\hline $\mathrm{A} 29^{32}$ & Brazil & Integrative Review \\
\hline $\mathrm{A} 30^{33}$ & Spain & Non-randomized controlled trial \\
\hline
\end{tabular}

The articles indicate five biological effects on patients with cancer induced by the use of music: reduction of anxiety, improvement of depression, easing of acute or chronic pain, variations on cardiorespiratory parameters and reduction of fatigue. Each biological effect was then analyzed separately.

\section{Reduction of anxiety}

Cancer provokes fear, anxiety and other emotional state disturbances that initiates symptoms capable of affecting the patients and their relatives. ${ }^{20}$ Anxiety is intensified between medical consultations as well as during the realization of laboratory tests and medical procedures, both of which alter the patient's biochemical profile, including increased levels of cortisol and adrenalin, for example. ${ }^{24,30}$

An example of music's potential to reduce levels of anxiety is the faster recovery from stress after listening to sounds of nature ${ }^{23}$. The application of music therapy in a pediatric oncology hospital was appointed was a family rapprochement facilitator in the context of coping with the disease, thanks to the distraction from the cause of anxiety promoted by the intervention $^{31}$. Amongst the articles that describe anxiety reducing, a North American randomized clinical trial including patients submitted to STAI-S (State-Trait Anxiety Inventory to State Anxiety) questionnaire before and after exposition to radiotherapy and music therapy affirms significant reduction on anxiety and stress levels in the group submitted to music therapy compared to control group ${ }^{4}$. Another North American article described reduction of both anxiety levels and time of hospitalization between patients who underwent breast cancer surgery and were exposed to live music and recorded music before and after the procedure, respectively. ${ }^{10}$. Patients who treat breast cancer generally adhere well to complementary therapies, being a group with good results from these interventions. 5,12

North American and Canadian articles observed, likewise, improvement of pediatric patients with cancer's mood and pattern of anxiety. ${ }^{17,18,19,33} \mathrm{~A}$ clinical study involving children attending ambulatory care to cancer disease follow-up exposed patients to 20 minutes of music in their second consultation, being the control group composed by the same patients, in their first consultation. It was attested promotion of comfort and relaxation after the intervention. ${ }^{26}$ An American systematic review evaluated the effects of music, along with other complementary therapies, on anxiety, mood disturbances, pain, quality of life and the incidence of collateral effects caused by conventional cancer therapies in patients with lung cancer, concluding the complementary therapies have positive effects on all the variables mentioned. ${ }^{13}$ A German study analyzed the impact of the intervention with art therapy, music therapy and dance on patients undergoing chemotherapy for breast cancer and concluded that those who were exposed to 15 minutes of music therapy during chemotherapy sessions for two weeks presented improvement in quality of life and of anxiety levels. 16

One North American study brings a counterpoint to the alternative intervention discussed above. Patients submitted to bone marrow biopsy when diagnosed with hematological cancer were put to listen to recorded music of their choice throughout the procedure. According to the study, the intervention did not have significant impact on anxiety improvement. $^{21}$

\section{Improvement of depression}

Depression is a disease whose conventional treatment arouses numerous challenges: the adherence to longterm therapy; the adverse effects of drugs - such as orthostatic hypotension, sedation, cardiac arrhythmias, among others; withdrawal syndrome associated to drug discontinuation and other pharmacological interactions. Being depression the most common psychiatric disorder between oncological patients ${ }^{34}$ and considering their expected emotional frailty, integrative and complementary health practices that act alongside drug interventions, 
potentializing recovery through psychological and biological effects, are of great value.

The effects of using music in mood and depression improvement in patients with cancer have been discussed throughout the last decades, as described by this review. Among the seven studies that composed the sample to this analytic category, five demonstrated benefits of the use of music therapy in oncologic patients with depression and two suggest the elaboration of more accurate studies so that such benefits might be specifically recommended. A Brazilian systematic review registered positive impacts of music therapy on mood, evaluating the total of 1.891 patients with cancer. ${ }^{28}$ North American systematic reviews gathered positive results of the use of music in patients with cancer and depression as well ${ }^{27}$ and described that women with cancer treated with music therapy after total mastectomy demonstrated significant improvement of depression, measured by the General Questionnaire e by the Chinese version of Zung Self-rating Scale for Depression. $^{22}$ Nevertheless, active music therapy, in the same studies, although related to immediate effects in the group under intervention, did not presented sustained results over time. Studies that compare directly the effects of active and passive music therapy are needed in order to comprehend whether the benefits come specifically from a technique or another.

A sole North American revision, on the use of complementary therapies in patients with lung cancer, considered the number of controlled studies insufficient to commend music therapy particularly. ${ }^{13}$

\section{Easing of acute or chronic pain}

World Health Organization defines neoplasm related pain as a medical emergency. About $50 \%$ of patients have pain during treatment and, with metastasis, the prevalence of pain raises from $25 \%$ to $30 \% .^{35}$ According to Saunder's concept of Total Pain (1967), pain encompasses physical aspects, due to tecidual damages; psychological aspects, like apathy and affection; social aspects, such as social isolation or good family relationships; and spiritual aspects, involving attribution of meaning to life and death. Such multidimensionality requires a management that is not restricted to analgesic medication and speaks in favor of integrative and complementary health practices as adjuvant treatment.

Concerning the effects of music on pain, a North American randomized clinical trial evidenced relevant decrease in pain score in patients under palliative care - mostly, oncologic patients - who received music therapy besides traditional medical care with analgesics compared to patients who received this last intervention only. ${ }^{8}$ A Chinese study pointed other two systematic reviews in which the intervention with music could be associated to pain easing, although moderate. ${ }^{15}$ A case-control study reported that patients with cancer facing stem-cells transplant affirmed reduction of pain after relaxation sessions with music. ${ }^{11}$ A Hawaiian integrative review and a American systematic review described reduction of pain during venous and lumbar puncture, respectively, in children with cancer. ${ }^{18,19}$ A German systematic review and meta-analysis reported results of pain easing due to use of music still in the preoperative period. ${ }^{16}$

It is worth to point that oncological pain does not come merely from the disease, but from the effects of chemotherapy and radiotherapy as well. In this sense, a North American study exhibited greater reduction of pain perception between women with breast and cervical malignant tumors under chemotherapy as they received, also, 20 minutes of music therapy twice a day. ${ }^{22}$

One study compared the differences between the impact caused by live music and recorded music, not verifying differences as regard to the dosage of anesthetic drugs required to sedation; there being, however, in both groups, some reduction of the dosage necessary for that. ${ }^{10}$

In order to reach the reduction of pain perception, the type of music therapy and the type of song may influence the results. According to a dutch study, songs chosen by the patient reduce the perception of pain because of comfort and familiarity sensations, whilst unknown songs produce results, preferentially, through cognitive mechanisms, instead of emotional. ${ }^{14} \mathrm{~A}$ Brazilian integrative reviews corroborates the potential of familiar songs as it proposes, observing experiences in diverse studies, that nurses offer songs known by the patient to complement their analgesia. ${ }^{28}$ Another Brazilian study, however, worked with previous choice of the song to be applied - Spring, from Vivaldi's Four Seasons, denoting, still, pain easing. The hypothesis includes the distraction from pain and the pituitary stimulation to release of endogenous opioids. ${ }^{32}$ One more Brazilian study supports the first hypothesis, affirming that music acts as a competitive stimulus against pain, because it redirects a person's attention, modulating pain stimulus unconsciously. ${ }^{29}$

The use of music to reduce oncological pain is still questioned by some authors. A German randomized clinical trial did not verify significant differences in pain perception between control group and the group which received music therapy. ${ }^{9}$

Considering that pain has an important aspect of subjective perception, the patients are the best parameter to define the outcomes of using music to relieve their pain. A North American randomized controlled trial corroborates this affirmation since, besides not finding statistically relevant differences 
in reduction of anxiety and pain between oncological patients submitted to bone marrow biopsy with and without the use of music as adjuvant therapy, it listens to patients' desire to repeat the intervention in future medical procedures for considering music clinically beneficial. ${ }^{21}$

\section{Variations on cardiorespiratory parameters}

Concomitant to mood variations that lead the patient with cancer to anxiety symptoms, there are cardiorespiratory variations due to the activation of sympathetic autonomic nervous system, which occurs in cases of stress. Frequent effects of conventional therapies are: arterial blood pressure, cardiac frequency and respiratory frequency raises. Complementary therapies may be useful to control these variations, which can accentuate anxiety disorders. Studies justify music effects on cardiorespiratory parameters based on the increase of endorphins and/or catecholamines release after listening to music. ${ }^{17}$

A Dutch study reports that patients under surgical rehabilitation cares have decrease in arterial blood pressure, cardiac frequency and respiratory frequency as they listen to classical music during recovery, compared to control group. ${ }^{14}$ A German systematic review verified decrease of arterial blood pressure and cardiac frequency in patients exposed to music in pre, intra and post-operative periods. ${ }^{16}$ A German clinical trial observed patients with cancer exposed to live music and also reported improvement of cardiorespiratory signs such as decrease of cardiac frequency and optimization of general well-being of terminal patients under palliative care. ${ }^{9}$ Another trial, North-American, related decrease of cardiac frequency, relaxation and greater levels of comfort and felicity between women with metastatic breast cancer exposed to music therapy. ${ }^{22}$

As a counterpoint, a North-American systematic review identified only a small variation of cardiorespiratory parameters in oncological patients submitted to music therapy, there being improvement of only some of the physical and mental criteria analyzed in this review.

\section{Reduction of fatigue}

Fatigue has a prevalence of $80-90 \%$ between patients with cancer treated with chemotherapy or radiotherapy. ${ }^{36}$ It consists of a subjective sensation of tiredness, which is disproportionate to the level of physical and mental activities. The nature of fatigue in oncological patients is related mainly to the effects of both the disease and treatment on central nervous system, but psychiatric, endocrine and cardiac causes cannot be discarded. These causes are not all reversible and drug treatments against fatigue are commonly inefficient.

Once again, the use of alternative therapies that work cognitive and emotional aspects of the symptom must be considered. Studies show that music therapy did reduce scores of fatigues in quality of life scales. ${ }^{9}$ Also, it is described that songs with fast pace may energize and improve mood of fatigued patients. ${ }^{25} \mathrm{An}$ American study confirmed these outcomes in pediatric patients as well. ${ }^{26}$

In the meantime, although referring improvement of fatigue in various studies analyzed, a Chinese overview of systematic reviews points that there are not sufficient results to provide strong recommendations in favor of music therapy. ${ }^{15} \mathrm{~A}$ North-American study relates a small to moderate effect of treatment with music therapy on fatigue, without strong evidences of physical functioning improvement in general. The use of more accurate oncological fatigue evaluation tools and the treatment of its reversible organic causes might facilitate a more proper analysis of music effects on this symptom.

\section{Other effects of music therapy with cancer patients}

It is important to point that, besides strictly biological effects, the use of music in oncological contexts also produces psychosocial and behavioral results that contributes to a better quality of life to the patient with the disease. Music therapy sessions applied to patients with cancer in terminal stage, especially active music therapy, facilitated nonverbal expression of suppressed emotions and verbal expression of questions such as treatment, future care and palliative care. Topics like death and spirituality were less prevalent. In sessions of receptive music therapy, it was described a smaller level of communication of such feelings, supposedly due to its greater focus on distraction and relaxation.

Active musical engagement of children with cancer and their parents has also been studied from the point of view of music effects on the stress these caregivers experience. It was verified reduction of stress in children, but not in their parents, because the active musical application and the parents' task of encouraging their children to remain engaged in the activity required greater levels of energy and concentration, causing a raise of stress between parents. ${ }^{6}$

\section{Conclusion}

Considering the integrality needed in patients with cancer's treatment and the frequent diagnosis of the disease in advanced stages, the approach must value quality of life, even in palliative care contexts. Before the evidences of reduction of anxiety, improvement of depression, easing of acute or chronic pain, variations on cardiorespiratory parameters and reduction of fatigue through the use of music in the context of oncological disease, such strategy stands out as an effective therapeutic possibility, 
noninvasive and of low costs.

It is proposed that music be more diffused as adjuvant intervention in the management of patients with cancer. Future research that corroborate and question the obtained results in selected populations can contribute to the construction, in hospitals and other host services to oncological patients, of a scenery in which music is part of a more integral, effective and humanized health care.

\section{References}

1. Silva LAGP, Mercês NNA. Multiple case study applied in nursing research: a case report. Rev Bras Enferm [Internet]. 2018;71(3):1194-7. DOI: http://dx.doi.org/10.1590/00347167-2017-0066

2. World Federation of Music Therapy, 1996.

3. Santos CMC, Pimenta Cibele Andrucioli de Mattos, Nobre Moacyr Roberto Cuce. A estratégia PICO para a construção da pergunta de pesquisa e busca de evidências. Rev. LatinoAm. Enfermagem [Internet]. 2007 June [cited 2018 Nov 28] ; 15( 3 ): 508-511. Available from: http://www.scielo.br/scielo.php?script=sci_arttext\&pid=S010 4-11692007000300023\&lng=en.

http://dx.doi.org/10.1590/S0104-11692007000300023.

4. Rosseti A, Chada M, Torres B, et al. - THE IMPACT OF MUSIC THERAPY ON ANXIETY IN CANCER PATIENTS UNDERGOING SIMULATION FOR RADIATION THERAPY. Int J Radiat Oncol Biol Phys. 2017 Sep 1;99(1):103-110. doi:

5. Greenlee H, DuPont-Reyes MJ, Balneaves LG, et al. Clinical practice guidelines on the evidence-based use of integrative therapies during and after breast cancer treatment. CA Cancer J Clin. 2017;67(3):194-232

6. Robb SL, Haase JE, Perkins SM, et al. Pilot Randomized Trial of Active Music Engagement Intervention Parent Delivery for Young Children With Cancer. J Pediatr Psychol. 2016;42(2):208-219.

7. Preissler, P., et al - favored subjects and psychosocial needs in music therapy in terminally ill cancer patients: a content analysis

8. Gutsell, KJ., et al. Music therapy reduces pain in palliative care patients: a randomized controlled trial - journal of pain and symptom management

9. Warth M, Keßler J, Hillecke TK, Bardenheuer HJ. Music Therapy in Palliative Care. Dtsch Arztebl Int. 2015;112(46):788-94.

10. Palmer JB, Lane D, Mayo D, Schluchter M, Leeming R. Effects of Music Therapy on Anesthesia Requirements and Anxiety in Women Undergoing Ambulatory Breast Surgery for Cancer Diagnosis and Treatment: A Randomized Controlled Trial. J Clin Oncol. 2015;33(28):3162-8.

11. Chakraborty, R., et al. A perspective on complementary/alternative medicine use among survivors of hematopoietic stem cell transplant: benefits and uncertainties.

12. Greenlee $\mathrm{H}$, Balneaves LG, Carlson LE, et al. Clinical practice guidelines on the use of integrative therapies as supportive care in patients treated for breast cancer. $J$ Natl Cancer Inst Monogr. 2014;2014(50):346-58.

13. Cassileth BR, Deng GE, Gomez JE, Johnstone PA, Kumar N, Vickers AJ.

14. Complementary Therapies and Integrative Oncology in Lung Cancer. CHEST vol. 132 , Issue 3, 340S - 354S

15. Pauwels EK, Volterrani D, Mariani G, Kostkiewics M. Mozart, music and medicine. Med Princ Pract. 2014;23(5):403-12.

16. Yanju Bao, Xiangying Kong, Liping Yang, et al., "Complementary and Alternative Medicine for Cancer Pain: An Overview of Systematic Reviews," Evidence-Based Complementary and Alternative Medicine, vol. 2014, Article ID $170396, \quad 9 \quad$ pages, 2014 https://doi.org/10.1155/2014/170396

17. Boehm K, Cramer H, Staroszynski T, Ostermann T. Arts therapies for anxiety, depression, and quality of life in breast cancer patients: a systematic review and meta-analysis. Evid Based Complement Alternat Med. 2014;2014:103297.

18. Poder TG, Lemieux R. How effective are spiritual care and body manipulation therapies in pediatric oncology? A systematic review of the literature. Glob J Health Sci. 2013;6(2):112-27. Published 2013 Dec 10 doi:10.5539/gjhs.v6n2p112

19. Landier W, Tse AM. Use of complementary and alternative medical interventions for the management of procedurerelated pain, anxiety, and distress in pediatric oncology: an integrative review. J Pediatr Nurs. 2010;25(6):566-79.

20. Thrane S, "Effectiveness of integrative modalities for pain and anxiety in children and adolescents with cancer: a systematic review" Journal of pediatric oncology nursing : official journal of the Association of Pediatric Oncology Nurses vol. 30,6 (2013): 320-32.

21. Archie P, Bruera E, Cohen L. Music-based interventions in palliative cancer care: a review of quantitative studies and neurobiological literature. Support Care Cancer. 2013;21(9):2609-24

22. Danhauer SC, Vishnevsky T, Campbell CR, et al. Music for patients with hematological malignancies undergoing bone marrow biopsy: a randomized controlled study of anxiety, perceived pain, and patient satisfaction. J Soc Integr Oncol. 2010;8(4):140-147.

23. Mind-body therapies: evidence and implications in advanced oncology practice. J Adv Pract Oncol. 2012;3(6):357-73.

24. Valenti VE, Guida HL, Frizzo AC, Cardoso AC, Vanderlei LC, Abreu LC. Auditory stimulation and cardiac autonomic regulation. Clinics (Sao Paulo). 2012;67(8):955-8.

25. Music therapy in supportive cancer care. Rep Pract Oncol Radiother. 2011;16(5):170-2. Published 2011 Jun 8 doi:10.1016/j.rpor.2011.04.005 (aqui não cita nem o nome do autor. Nas informações da revista há recomendações mais específicas. Mas peguei do "citation" formato AMA do pubmed. É isso mesmo?)

26. Kwekkeboom KL, Cherwin CH, Lee JW, Wanta B. Mindbody treatments for the pain-fatigue-sleep disturbance symptom cluster in persons with cancer. J Pain Symptom Manage. 2009;39(1):126-38.

27. Kemper KJ, Hamilton CA, McLean TW, Lovato J. Impact of music on pediatric oncology outpatients. Pediatr Res. 2008;64(1):105-9.

28. Bradt J, Dileo C, Magill L, Teague A. Music interventions for improving psychological and physical outcomes in cancer patients. Cochrane Database of Systematic Reviews 2016 , Issue 8. Art. No.: CD006911. DOI 10.1002/14651858.CD006911.pub3.

29. Silva Vladimir Araujo da, Leão Eliseth Ribeiro, Silva Maria Júlia Paes da. Assessment of quality of scientific evidence on musical interventions in caring for cancer patients. Interface (Botucatu) [Internet]. 2014 Sep [cited 2018 Nov 28] ; 18( 50 ): 479-492. Available from: http://www.scielo.br/scielo.php?script=sci_arttext\&pid=S141 4-32832014000300479\&lng=en. Epub Aug 01, 2014 http://dx.doi.org/10.1590/1807-57622013.0875.

30. Seki, N.H.; Galheigo, S.M. The use of music in palliative care: humanizing care and facilitating the farewell. Interface Comunic., Saude, Educ., v.14, n.33, p.273-84, abr./jun. 2010

31. Nightingale, C. L., Rodriguez, C., \& Carnaby, G. (2013). The Impact of Music Interventions on Anxiety for Adult Cancer Patients: A Meta-Analysis and Systematic Review. Integrative Cancer Therapies, 12(5), 393-403. https://doi.org/10.1177/1534735413485817 (aqui o site não tinha o formato AMA, somente APA, Chicago, Harvard, MLA. Usei o APA)

32. Firmeza Mariana Alves, Rodrigues Andrea Bezerra, Melo Geórgia Alcântara Alencar, Aguiar Maria Isis Freire de, Cunha Gilmara Holanda da, Oliveira Patrícia Peres de et al Uso da música no controle da ansiedade em ambulatório de cabeça e pescoço: ensaio clínico randomizado. Rev. esc. 
enferm. USP [Internet]. 2017 [cited 2018 Nov 28] ; 51: e03201. Available from: http://www.scielo.br/scielo.php?script=sci_arttext\&pid=S008 0-62342017000100404\&lng=en. Epub Mar 27, 2017. http://dx.doi.org/10.1590/s1980-220x2016030503201.

33. Sepúlveda-Vildósola, AC, Herrera-Zaragoza, OR, JaramilloVillanueva, L, Anaya-Segura, A. La musicoterapia para disminuir la ansiedad. Su empleo en pacientes pediátricos con cáncer. Revista Médica del Instituto Mexicano del Seguro Social [Internet]. 2014;52(2):S50-S54. Recuperado de: http://www.redalyc.org/articulo.oa?id=457745486009

34. 33 Bottino Sara Mota Borges, Fráguas Renério, Gattaz Wagner Farid. Depressão e câncer. Rev. psiquiatr. clín. [Internet]. 2009 [cited 2018 Nov 28] ; 36( Suppl 3 ): 109$115 . \quad$ Available from: http://www.scielo.br/scielo.php?script=sci_arttext\&pid=S010 $1-60832009000900007 \& \ln \mathrm{g}=\mathrm{en}$.

http://dx.doi.org/10.1590/S0101-60832009000900007.
35. Karen Mendes, Costa Junior Aderson Luiz, Rolim Gustavo Sattolo. Dor em oncologia: intervenções complementares e alternativas ao tratamento medicamentoso. Temas psicol. [Internet]. 2010 [citado 2018 Nov 28] ; 18( 2 ): 345-355 Disponível em: http://pepsic.bvsalud.org/scielo.php?script=sci_arttext\&pid= S1413-389X2010000200009\&lng=pt.

36. Borges Jacqueline Aparecida, Quintão Mônica Maria Pena, Chermont Sergio S. M.C., Mendonça Filho Hugo Tannus Furtado de, Mesquita Evandro Tinoco. Fadiga: Um Sintoma Complexo e seu Impacto no Câncer e na Insuficiência Cardíaca. Int. J. Cardiovasc. Sci. [Internet]. 2018 Aug [cited 2018 Nov 28] ; 31( 4 ): 433-442. Available from: http://www.scielo.br/scielo.php?script=sci_arttext\&pid=S235 9-56472018000400433\&lng=en. http://dx.doi.org/10.5935/2359-4802.20180027. 